\title{
Sentido e importância do "Direito" nos cursos de Graduação
}

\section{Meaning and importance of "Law" in Undergraduate courses}

\section{Significado e importancia del "Derecho" en los cursos de Pregrado}

\author{
Pedro Laudinor Goergen ${ }^{1}$
}

DOI: http://dx.doi.org/10.20435/serie-estudos.v20i52.1356

\begin{abstract}
Resumo: Este artigo busca apresentar uma reflexão a respeito de como a pessoa constrói/ reconstrói a noção de Sujeito de Direito enquanto cidadã, com o objetivo de assegurar a Dignidade humana. Nesses termos, foi desenvolvido um estudo a respeito dos saberes do Direito. A análise realizada permite perceber que a práxis educacional, materializada na dialética entre Educação e Direito, possibilita conceber o Sujeito de Direito a partir da percepção de 'valor absoluto' atinente a todo ser humano. $\mathrm{O}$ artigo é proveniente de um estudo qualitativo de cunho bibliográfico. $\mathrm{O}$ estudo apresenta resultados fundamentados em uma pesquisa empírica, evidenciando que a materialização do conhecimento significativo, fruto também da inclusão do saber jurídico no currículo de todas as graduações, deve ser aperfeiçoado nas Instituições de Ensino Superior responsáveis pela formação humanística do estudante.
\end{abstract}

Palavras-chave: Direito; cursos de graduação; Sujeito de Direito.

Abstract: This article aims to present a reflection on how the person builds/reconstructs the notion of Subject of Law as a citizen, in order to ensure human dignity. Accordingly, a study on the knowledge of law was developed. The analysis allows us to realize that the educational praxis, materialized in the dialectic between Education and Law, makes it possible to conceive the Subject of Law from the perception of 'absolute value' pertaining to every human being. The article comes from a qualitative study of bibliographic nature. The study presents results based on an empirical research, showing that the materialization of meaningful knowledge, also fruit of the inclusion of legal knowledge in the curriculum of all undergraduates, should be improved in the Higher Education Institutions responsible for the humanistic formation of the student.

Keywords: Law; undergraduate courses; Subject of Law.

Resumen: Este artículo tiene como objetivo presentar una reflexión sobre cómo la persona construye/reconstruye la noción de sujeto de derecho como ciudadano, a fin de garantizar la

1 Universidade de Sorocaba (Uniso), Sorocaba, São Paulo, Brasil. 
Dignidad humana. En consecuencia, se desarrolló un estudio sobre el conocimiento del derecho. El análisis nos permite darnos cuenta de que la praxis educativa, materializada en la dialéctica entre Educación y Derecho, hace posible concebir al Sujeto del Derecho a partir de la percepción del "valor absoluto" de cada ser humano. El artículo proviene de un estudio cualitativo de naturaleza bibliográfica. El estudio presenta resultados basados en una investigación empírica, que muestra que la materialización del conocimiento significativo, también resultante de la inclusión del saber legal en el reanudar de todos los estudios de pregrado, debe mejorarse en las Instituciones de Educación Superior responsables per la formación humanística del estudiante.

Palabras clave: Derecho; cursos de pregrado; Sujeto de Derecho.

\section{INTRODUÇÃO}

Pode-se dizer que hoje é consensual a tese de que a pessoa humana é, desde o seu nascimento, Sujeito de Direito. Não obstante, a experiência do convívio digno e respeitoso entre Sujeitos de Direito exige regras de conduta social juridicamente convalidadas. Disso decorre que a garantia dos direitos de cada um implica a obrigação do respeito aos direitos dos outros. Delineia-se, pois, como o ser humano efetivamente constrói/reconstrói a noção de Sujeito de Direito como cidadão, dentro de um sistema democrático de Direito, com o objetivo de assegurar a Dignidade humana, no cenário das relações sociais.

Uma sociedade democrática, organizada segundo os princípios do Estado Democrático de Direito, deve "mapear" as condições necessárias para a transformação do indivíduo em Sujeito de Direito, o que decorre da materialização dos chamados direitos públicos subjetivos ${ }^{2}$. Dessa constatação decorre que os saberes essenciais à compreensão dos valores da pessoa humana em sociedade, além de convencionados juridicamente, devem ser trabalhados a fim de se "formar" o Sujeito de Direito em sintonia com a materialização dos direitos dos cidadãos.

O que se pretende na presente reflexão, embasada em pesquisa empírica, é argumentar e justificar a presença do componente curricular Direito no currículo de todos os cursos da educação superior. O pressuposto básico é de que as pessoas com acesso à educação superior, ao posteriormente assumirem posição de

2 A respeito da consagração dos direitos subjetivos, Abboud, Carnio e Oliveira (2015, p. 286) preceituam que "todo o ordenamento jurídico, fundado no ser humano, pressupõe uma capacidade jurídica que implica na formação do próprio direito subjetivo. Portanto, ignorar a categoria do direito subjetivo termina por formar sistema jurídico que não está centrado no próprio homem”. 
destaque e influência social, tornam-se responsáveis tanto por sua própria postura profissional quanto pela construção de uma sociedade democrática de Direito.

\section{SABER SIGNIFICATIVO E ESSENCIAL PARA A FORMAÇÃO HUMANÍSTICA DO UNIVERSITÁRIO}

A Constituição Federal do Brasil de 1988, ao perfilhar o Estado Democrático de Direito, reconhece o direito dos cidadãos e, sobretudo, garante o respeito aos direitos sociais, entre os quais se destaca o da Educação, constitucionalmente assegurado a todos, em igualdade. De acordo com o art. 6으 do texto constitucional:

São direitos sociais à educação, a saúde, a alimentação, o trabalho, a moradia, o transporte, o lazer, a segurança, a previdência social, a proteção à maternidade e à infância, a assistência aos desamparados, na forma desta Constituição³. (BRASIL, 2016).

Pode-se, então, afirmar que a Educação, quando assegurada a todos em igualdade, visa garantir a Cidadania, uma vez que "[...] o pensamento sócio-político-pedagógico progressista reconheceu e proclamou a cidadania como direito e a educação como garantia da cidadania" (ARROYO, 2010, p. 1403). A noção de Cidadania é uma expressão oriunda do Estado de Direito que prevê, em seu Ordenamento Jurídico ${ }^{4}$, a igualdade entre as pessoas, ou seja, é inerente ao Estado a ideia de Cidadania em suas perspectivas socioculturais, incluindo os seres humanos na classe de possuidores de direitos e deveres, desde o momento em que são considerados existentes, a partir do seu nascimento ${ }^{5}$. A Cidadania pode, também, ter como condição distinguir uma pessoa da outra, na medida em que uma pessoa é ela mesma e nenhuma outra:

3 A Constituição Federal prevê que os direitos sociais serão garantidos em igualdade, conforme prescreve em seu art. 5o: "Todos são iguais perante a lei, sem distinção de qualquer natureza [...]" (Redação dada pela Emenda Constitucional n. 90, de 2015) (BRASIL, 2016).

4 Entende-se que o ordenamento jurídico compreende o conjunto, ou o complexo, ou o sistema de normas jurídicas, ou, na definição de Bobbio (2014, p. 45), "[...] o ordenamento jurídico (como todo sistema normativo) é um conjunto de normas".

5 O art. 2o do Código Civil (Lei n. 10.406/02, de 10 de janeiro de 2002) prescreve que "a personalidade civil da pessoa começa do nascimento com vida; mas a lei põe a salvo, desde a concepção, os direitos do nascituro" (BRASIL, 2016). 
Vista sob esse aspecto, a cidadania é um duplo na identidade do homem. Na esfera individual, cada um é único e inigualável; na esfera pública, cada um é um cidadão, teoricamente igual a todos os outros assim considerados. (FERREIRA, 1993, p. 20)

Do ponto de vista do Estado de Direito, subentende-se que o acesso à Educação é um direito de todo ser humano pelo "simples" fato de ser pessoa humana detentora de direitos. Com fundamento na igualdade que deve ser reconhecida em todas relações sociais, pode-se enfatizar que:

[...] o princípio da igualdade [...], nas Constituições democráticas, não se limita mais à mera proibição de discriminação, ele adquire dimensão promocional como mecanismo de acesso a bens fundamentais de convivência civil, tal como direito à educação, saúde e os direitos sociais. (ABBOUD; CARNIO; OLIVEIRA, 2015, p. 299).

Esse entendimento se materializa, juridicamente, no Ordenamento Jurídico Brasileiro, mais especificamente, no artigo 205 da Constituição Federal de 1988: o direito à Educação é o meio primordial para o desenvolvimento da pessoa humana, com o fim de conquistar o pleno exercício da Cidadania. Nessa perspectiva, o Estado brasileiro, com o objetivo de concretizar esse direito, constitucionalmente previsto no Sistema Jurídico, promove o acesso à Educação por meio das instituições educativas dos vários níveis, incluindo as universidades, que, auxiliadas pela sociedade, devem promover os saberes necessários à manutenção dos valores do ser humano em comunidade, essenciais para a construção do Sujeito de Direito.

A compreensão desses valores é fundamental, principalmente para o estudante universitário, porque, ao apreender os saberes significativos por meio da Educação, favorecerá seu envolvimento livre e reflexivo no universo social em que vive e trabalha, ou pretende trabalhar. E, como esse envolvimento é resultado de um direito constitucional, esse processo deve se efetivar de forma digna, crítica, livre e justa, uma vez que "educar o homem para a cidadania não é mais um dilema, mas um imperativo social" (FERREIRA, 1993, p. 22).

$\mathrm{O}$ acesso à Educação inclui, em sentido amplo, a prerrogativa de acesso à educação superior, visando à aquisição de conhecimentos significativos, especialmente os profissionalizantes. Na verdade, o Estado tem por obrigação constitucional garantir a igualdade de acesso à educação superior, favorecendo, assim, a concretização da Cidadania, pois "o pressuposto desse direito ao conhecimento é a igualdade" (CURY, 2014, p. 486). 
Ressalta-se que a concepção de conhecimentos significativos se relaciona aos saberes essenciais ao universo do aluno universitário, ou seja, aqueles saberes capazes de potencializar e materializar o fim desejado pela Educação: o desenvolvimento subjetivo e profissional do indivíduo e, por consequência, o desenvolvimento social, cultural e político da sociedade. Nesse sentido,

Ao formar as novas gerações com o espírito de um cidadão do mundo, a educação superior está contribuindo, desse modo, à própria formação da cidadania democrática [uma vez que] [...] a ideia de uma boa formação profissional exige a educação para a cidadania democrática. (DALBOSCO, 2015, p. 137-29, grifos nossos).

Nesse sentido, o direito à Educação pode e deve ser considerado imprescindível para o desenvolvimento pessoal e profissional, de liberdade e Cidadania, dos estudantes enquanto pessoas que vivem em sociedade e têm acesso ao conhecimento como bem público. Considerar o conhecimento como bem público é essencial à universidade destacando o seu principal aspecto, significa assumir que o conhecimento é uma das vertentes essenciais à manutenção e ao desenvolvimento da sociedade. O desenvolvimento pessoal e profissional do estudante cidadão se correlaciona, em mútuo sentido, ao desenvolvimento social, cultural e político da sociedade (DIAS SOBRINHO, 2005). Nesse sentido, vale lembrar a referência que Dias Sobrinho (2014a, p. 21) faz a respeito do papel das universidades:

[...] o que centralmente importa para a refundação da Universidade é a recuperação dos valores públicos fundamentais da humanidade. Dessa forma, aliada às demais forças sociais responsáveis, estaria a Universidade retomando sua função primordial de contribuir para a construção de uma verdadeira sociedade do conhecimento e da globalização da justiça e da dignidade humana. (grifos nossos).

O direito de acesso à educação superior é, então, correlacional à Cidadania de quem busca o conhecimento para sua formação pessoal e profissional. Além do acesso universal e equitativo ao conhecimento profissionalizante, é necessário buscar

[...] uma educação que não descuidasse da vocação ontológica do homem, a de ser sujeito e, por outro lado, de não descuidar das condições peculiares de nossa sociedade em transição, intensamente mutável e contraditória. [...] Educação, afinal, que promovesse a "ingenuidade", característica da 
imersão, em criticidade, com a qual o homem opta e decide. (FREIRE, 1997, p. 66, grifos nossos).

Nota-se, portanto, que a Cidadania vai além da simples aquisição de conhecimentos e conteúdos técnicos. Necessita-se a promoção de saberes subjetivos, políticos e culturalmente significativos. É nesse mister que se deve procurar a resposta para "o que é, hoje, educar para a cidadania? [...]" (FERREIRA, 1993, p. 11-2). O cenário da resposta nos é apresentado por Cury $(1988$, p. 103) nos seguintes termos:

O nível universitário deve ir além do mero ensino, deve envolver-se com a cultura desinteressada e com a pura ciência e exercer no meio social a influência educativa que seja a base das atuais necessidades de nosso aperfeiçoamento, técnico, científico e cultural. [...] A universidade mais do que o treino para esta ou aquela profissão, é treino para a "carreira do homem".

Nesse sentido, pode-se afirmar que o direito de acesso à Educação e à efetiva aquisição do conhecimento em nível superior não será capaz de, por si só, transformar o pensar do estudante em um pensar livre e crítico, imprescindível à Cidadania. Essa transformação pressupõe uma análise do universo em que se vive, com base em aprendizagem significativa capaz de promover mais consciência, liberdade e autonomia. Adverte-se, então, que:

[...] a luta pela cidadania não passa, apenas, pela conquista da igualdade de direitos para todos os seres humanos, mas também pela conquista de uma vida digna, na sua ampla acepção, para todos os cidadãos do planeta. Esta tarefa pressupõe a educação de todos com o objectivo de promover uma cidadania pautada na democracia, na justiça, na igualdade e na participação activa de todos os membros da sociedade. (PEREIRA; PEDRO, 2009, p. 106, grifos nossos).

É por esse motivo que se pode dizer que o ensino superior, por meio da prática pedagógica previamente delineada mediante uma matriz curricular bem elaborada, deve proporcionar soluções a questões que versem sobre ensinar e aprender mediante uma reflexão sistemática, adotando respostas pedagógicas fundamentadas na dialética teoria-prática. Isso porque constrói-se, a partir da realidade, do mundo social e cultural, o local em que a práxis educacional opera.

O ensino superior tem, além da aprendizagem de conhecimentos e habilidades profissionais, a primordial função de fomentar o nível de consciência crítica com relação à cultura existente em uma determinada sociedade. Nesse sentido, 
compreende-se que o saber, presente no ensino superior, não deve se limitar à função utilitária e restrita do conhecimento científico relativo ao campo de cada área profissional almejada. $O$ docente não deve ser apenas um profissional atento à competente aprendizagem de conhecimentos e habilidades profissionais, mas, também, ser um profissional com responsabilidade pela formação da Cidadania da pessoa humana:

[...] podemos dizer que ensinar e pesquisar devem ser gestos responsáveis [...], [pois,] além de construir e transmitir conhecimentos, cabe ao professor universitário a intransferivel tarefa de construir para a formação e a conscientização dos seus alunos. (GOERGEN, 2001, p. 64, grifos nossos).

\section{CIÊNCIA JURÍDICA E ATO EDUCATIVO}

A identidade do ser humano e suas experiências do dia a dia são construídas em determinado contexto cultural que deve ser o esteio das práticas educacionais, visando buscar elos entre o mundo profissional, o mundo cultural e a indispensável dimensão ética inexcusável à vida em sociedade. Ressalta-se que a cultura é, bem ou mal, a base de referência para o reconhecimento da relevância do conhecimento ministrado nas instituições escolares de todos os níveis. Nas palavras de Goergen (2005, p. 70),

Esta é uma das questões fundamentais que se colocam hoje para a teoria da educação: quais os fundamentos do nosso proceder educativo; com fundamento em quais princípios fazemos a seleção dos conteúdos que ministramos e dos métodos que usamos. Se cada tipo de vida desenvolve histórica e culturalmente uma maneira de representar o mundo e se estas formas têm em princípio os mesmos direitos, como saber qual a forma de ver o mundo que deve ser selecionada e administrada?

O único caminho para responder a esta questão é a postura crítica diante da realidade social que tem como critério último o bem-estar do indivíduo e da sociedade. O que está em jogo é, em última análise, a forma de ser do humano em sociedade. A realidade social concebida pelo conhecimento significativo, delineado no contexto da educação superior, visa compreender a relação entre os conhecimentos técnico-profissionais e os saberes culturais de determinada sociedade. A partir desta postura se concretiza o ato educativo, referente à "função fundamental do ensino superior de servir e promover a cultura comum 
nacional [...], [em termos] de sua função de formadora da cultura nacional e da cultura científica chamada pura ou 'desinteressada'" (TEIXEIRA, 1989, p. 156 e 166). Significa dizer que a Educação delimita a realidade social, por meio da percepção de sua concretude, articulada no tempo e no espaço, com a finalidade de estimular a recepção do conhecimento social desenvolvido, capaz de reproduzir e de questionar a cultura ${ }^{6}$. Para a construção cultural, contam, nessa situação, as experiências vividas, tanto pelo docente quanto pelo discente, colocando em tela de juízo a relação entre as práticas sociais, os conhecimentos e os parâmetros éticos delineados pela realidade social concreta, de um lado, e a ciência objeto de estudo, de outro.

Com o objetivo de materializar o ato educativo, a universidade, enquanto instituição social, deve ser considerada, também, como um dos agentes de socialização responsável pela formação cultural de seus alunos. Se, de um lado, tem razão Teixeira (1989, p. 151) ao afirmar que "uma das funções primaciais da universidade é cultivar e transmitir a cultura comum nacional", de outro, é preciso considerar de equivalente importância a postura crítica diante desta mesma realidade.

Ademais, percebe-se que toda prática social, por ter uma dimensão cultural, produz significados e com eles se relaciona, resultando na identidade dos sujeitos receptores da cultura. Trata-se, pois, do processo de socialização necessário para que se possa concretizar a sustentação e evolução da sociedade. Nessa perspectiva, utiliza-se o fundamento de que:

A educação é parte da sociedade; qualquer que seja ela, tenha sido ou venha a ser [...]. Mas para entender o seu sentido mais profundo, é preciso buscar este todo maior de que faz parte, a sociedade que a perpassa. [...] a educação é o fator de equilíbrio e manutenção da sociedade, na medida em que transmite os valores, costumes, hábitos e saberes de uma sociedade, seja através dos processos informais de socialização, seja mediante a educação formal, escolar. (MARQUES, 2014, p. 756, grifos nossos).

Assim, a cultura a ser desenvolvida pela Instituição de Ensino Superior faz

\footnotetext{
6 Na sociedade, as relações humanas produzem todo tipo de transformação e formam o meio de expressão e de comunicação do ser humano. Tudo o que é produzido pelo ser humano é denominado cultura, organização estruturante da sociedade ou do sistema social. Deve-se ressaltar que a cultura é o meio de construção da identidade do indivíduo em uma determinada sociedade (GIDDENS, 2005).
} 
com que a sociedade consiga manter as inter-relações que existem entre seus indivíduos, que passam a conhecer e valorizar criticamente os saberes e as práticas sociais, porque:

Todas as sociedades são unidas pelo fato de que seus membros são organizados em relações sociais estruturadas, de acordo com uma cultura única. Nenhuma cultura poderia existir sem sociedade. Mas, igualmente, nenhuma sociedade poderia existir sem cultura. Sem cultura, não seríamos sequer "humanos", no sentido em que comumente entendemos o termo. (GIDDENS, 2005, p. 38, grifos nossos).

Em termos do ponto de vista sociológico, concebe-se a noção de 'sistema', cujo núcleo é a imagem da realidade como um todo orgânico, sem, no entanto, reduzi-lo à empobrecida imagem de mera soma das partes. Assim entendida, a visão sistêmica ou holística considera que o conhecimento especializado não deve ser um fim em si, mas apenas um viés de leitura da realidade, cujo sentido se complementa pela visão do todo. Para entender o que é o todo, é preciso abandonar a imagem de um organismo composto pela soma mecânica de partes. Na visão de Morin (1994, p. 137-8 apud MARQUES, 2014, p. 756),

[...] onde o todo se constitui de componentes que se interligam numa rede de relações, de mútuas influências, cuja dinâmica se inscreve no plano da possibilidade e não na determinação; é o espaço tanto do acaso, como o da criação, do conhecimento.

No pensamento sistêmico, entende-se que tudo está interligado com tudo, materializando a realidade enquanto um todo que se constitui de diversos elementos e componentes ou, como explica Capra (2006, p. 46 e 48),

O universo material é visto como uma teia dinâmica de eventos inter-relacionados. Nenhuma das propriedades de qualquer parte dessa teia é fundamental; todas elas resultam das propriedades das outras partes, e a consistência global de suas inter-relações determina a estrutura de toda a teia.

A abordagem sistêmica entende a sociedade como um sistema referente ao todo organizado, estruturado e dinâmico, advindo das relações da sociedade e busca de sua manutenção. Nesses termos,

A noção de "sistema" é empregada em diferentes campos da ciência e, em regra, para indicar que os fenômenos investigados ocorrem segundo 
condições que permitem descrevê-los e interpretá-los como elementos ou partes interdependentes de um todo ordenado. Portanto, [...] os fenômenos sociais participam das propriedades dos outros fenômenos da natureza que se organizam em sistema. (FERNANDES, 1970, p. 85).

O sistema traduz, pois, uma visão holística da realidade e demonstra que, se o conhecimento for fragmentado, perde-se parte do seu sentido funcional e relacional. Se compreendido no contexto do todo maior, ao contrário, consegue-se vislumbrar as acepções que emergem das próprias relações e interações internas do objeto.

Nesse contexto do 'todo', ressalta-se que toda realidade social pode ser vista como um sistema social e, da mesma maneira, parte dessa realidade também pode ser analisada como um todo enquanto subsistema social. Isto quer dizer que a sociedade pode ser analisada tanto como sistema mais amplo quanto como um subsistema desse todo maior, como é o caso da Educação. Assim, é possível entender a realidade de cada sistema ou subsistema em seus aspectos relevantes, o que é fundamental tanto para a compreensão quanto para a ação (FERNANDES, 1970).

Entende-se, pois, que as sociedades humanas são um sistema que, para se manter e se adaptar, possui funções específicas, realizadas por suas instituições. Este é caso da Educação, que, na visão sistêmica, exerce uma função no âmbito maior da sociedade como um todo, mas que representa também um subsistema social mais restrito, com características próprias, que pode ser analisado enquanto tal. Esta imagem se aplica ainda à educação superior, porquanto ela representa um subsistema em relação ao sistema maior da Educação. Por essa razão, uma compreensão adequada da educação superior só pode ser alcançada na perspectiva maior do sistema educacional como um todo. Da mesma maneira, a Educação só pode ser plenamente compreendida no contexto, ainda maior, do sistema social. Esta lógica ascendente e descendente nos permite perceber a relevância do ato educativo da educação superior mediante o qual se concretiza, em última análise, o conhecimento significativo para a Educação e para a sociedade enquanto sistemas sociais que desvelam a cultura, cujo objetivo é o desenvolvimento da identidade do indivíduo e da sociedade em seu conjunto ${ }^{7}$.

7 A respeito da identidade do indivíduo em um sistema social, Giddens (2005, p. 43) enfatiza que: "os indivíduos passam a entender e a assumir papéis sociais por meio de um processo progressivo 
Assim, nessa perspectiva holística, espera-se que o aluno de graduação possa compreender o sentido de sua autoconstituição como ser individual e social e possa entender o significado disso para ele, a partir do momento em que compreende "sua" cultura e a vivência por meio do conteúdo constante nas diretrizes curriculares, referentes ao curso superior que escolheu. Significa dizer que o estudante universitário passa a conhecer e a compreender o universo em que se encontra, estando apto a reconhecer a si mesmo e a alcançar o conhecimento que combine seus interesses pessoais e sua formação profissional com o sentido social de suas opções. Dessa forma, o aluno de graduação torna-se capaz de pautar seu entendimento e sua postura social pelo pensar livre e crítico, a respeito de si mesmo e do mundo em que vive, assumindo uma aprendizagem significativa em termos de liberdade individual e de compromisso social.

O sistema, então, denota uma visão da realidade como um todo, mostrando que o conhecimento fragmentado só alcança plenitude na função social que deve ser almejada pelo sistema educacional. Nesse sentido, a realidade educacional deve ser concebida a partir do todo social, pois só assim aflora o real sentido do conhecimento a ser desenvolvido no contexto das práticas educativas.

A perspectiva holística tem enorme relevância porquanto é a única forma que permite dimensionar os sentidos e relevâncias de aprendizagens individuais, facetadas, parciais, desde um olhar abrangente. [...] Trata-se de uma nova leitura disciplinar que coloca ênfase numa perspectiva histórico/construtiva do conhecimento e não na apresentação asséptica de seus resultados. (GOERGEN, 2001, p. 71).

Para que o universitário possa compreender a realidade sociocultural, de maneira livre e autônoma, presente nos conteúdos curriculares, o saber que se encontra na educação superior deverá, então, abranger o conhecimento significativo a respeito do todo sociocultural. Ao partilhar o conhecimento socialmente significativo, as instituições de educação superior contribuem para a construção/ reconstrução da sociedade, embasadas em concepções socioantropológicas que visam trazer o sujeito para si, como pessoa e como ser social.

de interação social. [...] No decorrer da socialização, cada um de nós desenvolve um sentido de identidade e a capacidade para o pensamento e a ação independente. [...] a identidade se relaciona ao conjunto de compreensões que as pessoas mantêm sobre quem elas são e sobre o que é significativo para elas". 
Do ponto de vista da análise sistêmica, percebe-se, então, que o aluno tem a possibilidade de conhecer sua história e sua cultura (realidade social) como contextos identitários do ser humano e definidores de suas experiências formativas. Nesses termos, a dimensão política do processo pedagógico se institui como elemento fulcral da construção da Cidadania e da Dignidade humana.

Assim, pela dimensão holística, o conhecimento do todo decorre da evidência dada ao objeto formado pelas relações, ou interações, do objeto em si. Isso significa dizer que, no saber, trabalhado no ensino superior, há conteúdos que operam por meio das práticas multicontextualizadas ${ }^{8}$ nas formações sociais e no cenário de aproximações cognitivas da verdade do todo. A Educação, ao desenvolver o conhecimento significativo, incrementa a noção de sistema que se materializa no conteúdo do conhecimento significativo: o todo integrado, base do conhecimento estruturado, organizado e dinâmico da realidade, entrança-se nas práticas pedagógicas multicontextualizadas desenvolvidas de forma transversal ${ }^{9}$.

O sistema, então, traduz-se na visão holística da realidade, pois se refere à forma de se visualizar o todo, analisando-o de maneira organizada, estruturada e percebendo-o na forma dinâmica das relações sociais. Entende-se, ademais, a sociedade humana como um sistema; sistema social que se mantém com base em suas funções específicas realizadas por suas instituições, a exemplo da escola e de seus colaboradores. Ora, se entendemos a Educação como um subsistema do sistema social maior e constatamos, ademais, que esse subsistema é mantido, também, por distintas instituições, tais como família, Igreja, escola etc., conclui-se que a universidade é uma das instituições essenciais ao sistema social.

8 Realizar práticas pedagógicas multicontextualizadas possibilita a intersecção de diferentes práticas e transforma a matriz curricular em um instrumento do todo configurado como prática pedagógica nas instituições escolares, porque gera a expectativa de acesso ao conhecimento significativo, capaz de concretizar, na educação superior, o ato educativo.

${ }^{9}$ Conceber as práticas pedagógicas multicontextualizadas desenvolvidas de forma transversal significa que [...] o meio educativo ou o contexto de ensino supõe uma série de ambientes concêntricos, aninhados uns dentro de outros, com interferências e ocultamentos recíprocos, que dependem em grande medida ou se definem no modo de se desenvolver as tarefas, segundo a organização da escola e de acordo com as conexões da vida acadêmica com o ambiente exterior (SACRISTÁN, 2000, p. 230). 


\section{FORMAÇÃO PROFISSIONAL E HUMANÍSTICA DO UNIVERSITÁRIO}

A universidade, na concepção sistêmica, pode ser considerada uma instituição que tem função específica no contexto do sistema social, de modo geral, e no subsistema educacional, em particular. De um lado, a universidade contribui para a manutenção e adaptação do sistema, por exemplo, pela formação de profissionais e da produção e difusão de conhecimentos significativos; de outro, exerce (ou deveria exercer), também, a função de conscientização crítica pela formação de sujeitos conscientes e autônomos. A identidade subjetiva é construída a partir de elementos culturais que produzem significados e com eles interagem. No dizer de Giddens (2005, p. 43), "a identidade se relaciona ao conjunto de compreensões que as pessoas mantêm sobre quem elas são e sobre o que é significativo para elas". Nesses termos, o estudante, ao ser familiarizado com o conhecimento significativo pela universidade, compreende sua função social, possibilitando a construção de sua identidade sociocultural livre e cidadã.

Ao adquirir esses saberes no contexto da educação superior, o Sujeito de Direito se habilita para a construção e humanização da realidade social, superando barreiras e enxergando o sistema social como ele deveria ser, contribuindo para a efetivação de uma ordem social mais igual, digna e justa. Em sentido oposto às políticas atualmente em processo de implementação, segundo lembra Dias Sobrinho (2014b, p. 656),

A universidade ainda é a instituição com mais condições estruturais e humanas para fazer a crítica da sociedade, prever cenários de possibilidades, interrogar sobre os sentidos dos processos sociais e contribuir para a construção de uma real sociedade do conhecimento, para além da economia do conhecimento.

De uma parte, portanto, ao exercerem sua função de educação superior, as universidades atendem às expectativas do sistema, contribuindo para sua manutenção, e de outra, à formação de cidadãos conscientes, capazes de promover mudanças, melhorias ou mesmo a superação do modelo de organização social vigente. Essa dupla dinâmica pode se materializar por meio da matriz curricular e, por suposto, dos docentes, que colocam em prática, de maneira transversal e flexível, o conteúdo curricular em sala de aula. Nesse sentido, a matriz curricular que estrutura conhecimentos e práticas deve oferecer e promover saberes e práticas éticas essenciais à inserção e transformação cultural do todo social. Em outras 
palavras, o conteúdo pedagógico das Instituições de Ensino Superior deverá se relacionar com a realidade sociocultural, para que se alcance a manutenção e/ou transformação da sociedade e, ao mesmo tempo, para que se perfaçam os saberes desenvolvidos para o estudante cidadão, de forma a ganharem significado social.

No contexto das práticas educacionais universitárias, abre-se a possibilidade de desvelar a dinâmica da realidade e de promover a visão consciente e crítica do aluno. Para que essa função se materialize, é necessária a inclusão, de forma transversal, do conhecimento significativo, capaz de preparar o universitário para a vida pessoal e profissional, porque "todo processo de construção e difusão do conhecimento deve ser entendido como parte da práxis humana" (GOERGEN, 2001, p. 70).

A noção de sistema concretizada na matriz curricular decorre, então, do conhecimento estruturado, organizado e dinâmico da realidade, concebido de forma transversal e em conformidade com práticas pedagógicas multicontextualizadas, efetivadas na educação superior.

Para a formação do Sujeito de Direito, um dos principais recursos é a conquista e o estímulo ao pensamento livre e crítico, visando compreender e transformar, de maneira interconectada, o universo social onde está inserido o universitário. Para a realização desse propósito, será primordial, então, o trabalho de formação nas universidades, com a importante função de criar/recriar o pensar reflexivo e autônomo do indivíduo, com o objetivo de alcançar tanto melhor formação profissional quanto, em especial, boa formação pessoal, decisiva para a consciência cidadã, pressuposto essencial para uma sociedade mais humana, democrática e justa. A conquista desse objetivo pressupõe, além da criação de mecanismos político-sociais, a implementação de práticas formativas das quais faz parte a formulação de matrizes curriculares para os cursos de graduação, cujos conteúdos, além do conhecimento técnico especializado, devem contemplar conteúdos de formação humanística.

Isso significa que deve existir uma política pública que assegure a democratização dos saberes que, no caso concreto, ocorrerá também por meio de um sistema curricular adequadamente organizado. É o que prescreve a Resolução n. 1, de 30 de maio de 2012 (BRASIL, 2012), do Conselho Nacional de Educação, que "estabelece Diretrizes Nacionais para a Educação em Direitos Humanos", ao instituir a necessidade de inserir, "integrando os saberes acadêmicos", outros conhecimentos nos Currículos dos cursos superiores de graduação. 
Tal prescrição abre o necessário espaço para a inclusão do conhecimento jurídico, integrado e desenvolvido de forma transversal, já que o Direito é condição básica de construção da democracia e, nesse sentido, também da dimensão formativa plena do ser humano para a Cidadania. Uma das formas de implementar a relação entre formação profissional e humanista é, portanto, a inclusão do Direito como componente curricular que oportuniza a aquisição de conhecimentos jurídicos, base do convívio social. Ressalte-se, mais uma vez, que a inclusão dos saberes jurídicos deve, então, efetivar-se de maneira transversal aos alunos, uma vez que proporciona o diálogo entre o aprender sobre a realidade e o aprender na/para realidade, possibilitando aos estudantes a compreensão, autônoma e reflexiva, das regras e dos valores socioculturais (LAMARRA, 2014). Aqueles que têm acesso à compreensão de sua história e cultura jurídica tornam-se mais aptos a identificar e compreender, nas situações vivenciadas, as dimensões políticas fundamentais, consideradas primordiais para a Cidadania não só própria, mas de toda a sociedade. Possibilitar o acesso aos saberes jurídicos contribui para que a Educação, enquanto prática social organizada, promova o papel primordial do processo de ensino-aprendizagem, ou seja, a democratização dos saberes relativos ao pensar livre e crítico da Cidadania, uma vez que "o exercício democrático da cidadania exige a capacidade de pensar por si mesmo e desenvolvê-lo é tarefa primordial da educação" (DALBOSCO, 2015, p. 129-30).

Vale destacar a relevância da já mencionada Resolução n. 1, de 30 de maio de 2012 (BRASIL, 2012), do Conselho Nacional de Educação, porque concebe os Direitos Humanos como "um dos eixos fundamentais do direito à educação". Nessa perspectiva, pode-se esperar que a democratização dos saberes contribua para a efetivação da Cidadania, mediante o olhar do aluno/sujeito para si mesmo enquanto ser social, pois "a democracia verdadeira supõe um homem de espírito crítico, capaz de duvidar e de inquirir, um homem de iniciativas livres" (CURY, 1988, p. 102). Conforme destaca Freire (1997, p. 27),

O homem pode refletir sobre si mesmo e colocar-se num determinado momento, numa certa realidade: é um ser na busca constante de ser mais e, como pode fazer essa auto-reflexão, pode descobrir-se como um ser inacabado, que está em constante busca. Eis aqui a raiz da educação.

Importa garantir ao universitário o acesso aos saberes significativos para sua formação pessoal, integral e profissional, conforme orientação do Parecer do Conselho Nacional de Educação n. 776 de 3 de dezembro de 1997: 
Os cursos de graduação precisam ser conduzidos, através das Diretrizes Curriculares, a abandonar as características de que muitas vezes se revestem, quais sejam as de atuarem como meros instrumentos de transmissão de conhecimento e informações, passando a orientar-se para oferecer uma sólida formação básica, preparando o futuro graduado para enfrentar os desafios das rápidas transformações da sociedade, do mercado de trabalho e das condições de exercício profissional. (grifos nossos).

Nesses termos, a aludida Resolução n. 1, de 30 de maio de 2012, do Conselho Nacional de Educação, ao legislar a respeito da inclusão dos Direitos Humanos na educação superior, destaca a relevância, inclusive, de protegê-los mediante o acesso ao conhecimento significativo:

Art. 3ํ A Educação em Direitos Humanos, com a finalidade de promover a educação para a mudança e a transformação social, fundamenta-se nos seguintes princípios:

I- dignidade humana;

II- igualdade de direitos;

III- reconhecimento e valorização das diferenças e das diversidades;

IV- laicidade do Estado;

$\checkmark$ - democracia na educação;

$\mathrm{VI}$ - transversalidade, vivência e globalidade; e

VII- sustentabilidade socioambiental. (BRASIL, 2016, grifos nossos).

Percebe-se, então, que a conquista do direito ao acesso à educação liga-se à ideia de Cidadania e, consequentemente, à ideia de efetivação da Dignidade da pessoa humana. Isso porque, ao se motivar o desenvolvimento pessoal e profissional do universitário, desenvolvendo seu livre e crítico pensar, ele pode se tornar participativo em todos os movimentos sociais e políticos presentes em seu universo pessoal e profissional no contexto democrático garantido pelo sistema jurídico-político.

Denota-se, ademais, a compreensão utilitarista que assume prioridade: o conhecimento desenvolvido na Educação, em especial na educação superior, é imprescindível para se viver em sociedade. No entanto, o argumento aqui defendido é exatamente o de uma reação a esse pragmatismo utilitarista. Mesmo sem negar o sentido útil aplicado ao conhecimento, é preciso enfatizar que todas as atividades que integram a formação superior devem ter a percepção, também e inclusive, de busca, estímulo e conquista do pensamento livre e crítico do aluno. Dessa forma, o universitário poderá compreender com liberdade o mundo em 
que vive, conquistando, assim, condições para o exercício da Cidadania, pois "ser cidadão [...] é todo tempo fazer movimentos para não ser tomado pelas regulações, o que nos provoca para a invenção de uma outra universidade e outras formas de produção de conhecimento" (SANTOS; LAZZARATTO, 2007, p. 87-8).

Compreende-se que esse ideal se conquista na medida em que se tem a percepção de que o conhecimento é, na realidade, um direito de todos que vivem em uma sociedade democrática.

O direito de ter acesso à Educação é, pois, de todo indivíduo, segundo estabelecido pela Declaração Universal da Organização das Nações Unidas de $1948^{10}$ (ONU, 1948). Nesse mesmo sentido, salienta-se que a pessoa, então, poderá se formar Sujeito de Direito, a partir do momento em que consegue ter acesso ao processo educativo que proporciona saberes reais sobre a cultura de determinado tempo e lugar.

O estudante terá, então, a possibilidade de conhecer a realidade social, a fim de identificar-se como ser social e definir as situações que experimenta na Educação em relação às dimensões políticas fundamentais. O universitário poderá alcançar, na práxis educacional, uma visão pedagógica que não se encerra em sua experiência intelectual, mas se perfaz dentro de um universo educacional que visa fomentar a consolidação de sua Dignidade enquanto ser humano. Ao ser iniciado nessa práxis educacional pela universidade, o estudante compreende sua função social, possibilitando edificar a noção de Sujeito de Direito como cidadão, dentro de um sistema democrático de Direito. A identidade da pessoa é, então, arquitetada a partir de elementos culturais que produzem significados e com eles interagem: "a identidade se relaciona ao conjunto de compreensões que as pessoas mantêm sobre quem elas são e sobre o que é significativo para elas" (GIDDENS, 2005, p. 43).

Além disso, ao adquirir esses saberes, o Sujeito de Direito se torna eixo importante para a sociedade, porque será capaz de contribuir para a modificação da realidade social, superando barreiras em vista de um sistema social mais humano e democrático. Reconhecer sua identidade enquanto ser social significa realizar-se como pessoa, de tal forma que consiga se enxergar como um fim em si mesmo.

\footnotetext{
${ }^{10}$ Artigo I da Declaração Universal da Organização das Nações Unidas (ONU) de 1948: "Todos os seres humanos nascem livres e iguais em dignidade e direitos [...]" (grifos nossos).
} 
Por esse viés, compreende-se a necessidade de incorporar às práticas educacionais saberes capazes de criar/recriar os universos de interações socioeducativas e epistêmicas que contribuam para a construção de sua identidade. Isso porque a liberdade e a Cidadania só serão incorporadas pelo estudante, enquanto ser social, se forem fontes necessárias para a preservação do sentimento de Dignidade.

Conquistar a Dignidade pressupõe que a pessoa humana "tome consciência de seu valor", passando, então, a ser caracterizada e considerada como Sujeito de Direito, pois "o que caracteriza o ser humano, e o faz dotado de dignidade especial, é que ele nunca pode ser meio para os outros, mas fim em si mesmo" (SANTOS, 1999, p. 23).

A conscientização é, portanto, uma das condições sine qua non de concretização da Dignidade humana. Ora, o principal meio de se conquistar a conscientização ocorre pela/na Educação e, em especial, no ensino superior. É, então, por meio da prática educacional que o universitário, conscientemente, adquire autodeterminação e autonomia com relação às influências externas que visam a instrumentá-lo. Isso significa que, ao se reconhecer como valor, o aluno tem a possibilidade de adquirir conhecimentos essenciais de preservação e de garantia da Dignidade. Nesse sentido, a educação, enquanto direito de todos, torna-se importante agente de socialização, capaz de manter e/ou de efetivar a Dignidade, qualidade essencial de todo ser humano.

\section{CONCLUSÃO}

A argumentação presentada ao longo desse texto permite concluir que os direitos fundamentais deverão ser assegurados e reconhecidos a todo ser humano, em especial o direito ao acesso à Educação de/com qualidade, que promove a aprendizagem significativa. É por meio da Educação, em especial a de nível superior enquanto espaço de construção e reconstrução de conhecimentos, que se tem acesso a saberes significativos, abrangendo, inclusive, os referentes ao conteúdo jurídico, que podem favorecer o desenvolvimento pessoal, profissional e social. Esses conhecimentos favorecem a formação de um pensar livre e crítico, condição dos Sujeitos de Direito, com base em conteúdos articulados como fim almejado pela Educação.

Isso significa que deve existir uma política pública que assegure a democratização dos saberes que, no caso concreto, ocorrerá também por meio de um 
sistema curricular adequadamente organizado, conforme prescreve artigo 70 da Resolução n. 1, de 30 de maio de 2012, do Conselho Nacional de Educação, ao instituir a necessidade de inserir, integrando os saberes acadêmicos, os conhecimentos em Direitos Humanos. Por essa determinação, nota-se que a condição primordial à concepção da democracia decorre da inclusão do conhecimento jurídico, integrado e desenvolvido de forma transversal, no ensino superior de graduação.

Nesses termos, as matrizes curriculares, em especial as das instituições de educação superior, devem ser constituídas de forma a contemplar, além do conhecimento técnico/científico voltado para a formação profissional, também os saberes atinentes à formação cidadã dos futuros profissionais, para que possam se tornar partícipes efetivos da construção de uma sociedade mais justa e democrática.

Isso é possível a partir da construção de uma matriz curricular que contemple a formação para a Cidadania e a Dignidade da pessoa humana. O argumento aqui defendido é de que a presença do Direito na matriz curricular dos cursos de graduação proporciona aos alunos a compreensão a respeito do papel e da função político-social da educação superior preocupada com a formação cidadã dos seus estudantes. A educação superior é e deve ser capaz de proporcionar ao aluno de graduação o instrumental necessário para que tenha uma noção básica do Sistema Jurídico Brasileiro e, assim, possa conhecer, especificadamente, os direitos e os limites para sua atuação profissional, em consonância com a legislação vigente.

A elaboração de uma matriz curricular que permite o estudo de saberes jurídicos, bem como o estudo dos condicionantes que determinam a atuação do profissional, deverá proporcionar ao universitário a capacidade de distinguir as esferas da Moral, da Ética e do Direito, reconhecendo seus respectivos âmbitos e características, além de compreender e atuar de acordo com os direitos e os limites legais do exercício da profissão.

Dessa forma, evidencia-se que, ao disponibilizar o conhecimento jurídico ao estudante de graduação, haverá a democratização dos saberes, imprescindível para alcançar a Cidadania, porque permite, por meio do olhar do sujeito/estudante como um fim em si mesmo, torná-lo visível e participativo socialmente, de maneira livre e crítica, em todos os movimentos sociais e políticos vividos em seu universo pessoal e profissional. 
O aspecto de formação profissional e cultural deve fazer parte do projeto pedagógico da universidade, inclusive, considerando os conhecimentos jurídicos como elemento relevante para a matriz curricular de todos os cursos de graduação, inclusive para tornar operacional o sempre proclamado ideal da educação superior de promover o conhecimento como bem público, essencial ao progresso da sociedade. A partir do momento em que o universitário passa por um processo formativo que lhe proporciona o acesso tanto aos conhecimentos profissionalizantes quanto aos saberes culturais, incluindo os saberes jurídicos, efetivam-se as possibilidades de seu crescimento como sujeito autônomo e socialmente responsável. Reitera-se, portanto, que o saber jurídico deve estar presente no conteúdo curricular bem elaborado, porque poderá ser eficaz para disponibilizar conhecimentos e informações essenciais para o universitário viver/conviver em sociedade, uma vez que, ao concorrer para a formação técnica e humanística, poderá materializar o fim social da universidade: formar sujeitos humanos tecnicamente competentes e socialmente responsáveis.

\section{REFERÊNCIAS}

ABBOUD, Georges; CARNIO, Henrique Garbellini; OLIVEIRA, Rafael Tomaz de. Introdução à Teoria e à Filosofia do Direito. 3. ed. rev., ampl. e atual. São Paulo: Editora RT, 2015.

ARROYO, Miguel G. Políticas educacionais e desigualdades: à procura de novos significados. Educação \& Sociedade, Campinas, v. 31, n. 113, out./dez. 2010. p. 1381-416.

BOBBIO, Noberto. Teoria do Ordenamento Jurídico. Tradução de Ari Marcelo Solon. 2.ed. São Paulo: EDIPRO, 2014.

BRASIL. Vade Mecum RT. 12. ed. rev., ampl. e atual. São Paulo: Revista dos Tribunais, 2016.

BRASIL. Resolução n. 1, de 30 de maio de 2012. Resolução Conselho Nacional de Educação/ Conselho Pleno 1/2012. Diário Oficial da União, Brasília, 31 de maio de 2012. Seção 1, p. 48.

BRASIL. Ministério da Educação. Conselho Nacional de Educação. Parecer do Conselho Nacional de Educação n. 776, de 3 de dezembro de 1997. Disponível em: http://portal. mec.gov.br/cne/arquivos/pdf/1997/pces776_97.pdf. Acesso em: 4 dez. 2019.

CAPRA, Fritjof. A teia da vida: uma nova compreensão dos sistemas vivos. São Paulo: Cultrix, 2006. 
CURY, Carlos R. Jamil. Formação e conhecimento: perspectivas filosóficas e sociológicas. Avaliação: Revista da Avaliação da Educação Superior, Sorocaba, v. 19, n. 3, p. 603-29, nov. 2014.

CURY, Carlos R. Jamil. Ideologia e educação brasileira: católicos e liberais. 4. ed. São Paulo: Cortez Editora, 1988.

DALBOSCO, Cláudio Almir. Educação superior e os desafios da formação para a cidadania democrática. Avaliação: Revista da Avaliação da Educação Superior, v. 20, n. 1, Sorocaba, p. 123-42, mar. 2015.

DIAS SOBRINHO, José. Segundo Prefácio. In: BENTO, José Olímpio. Por uma univercidade anticonformista. Belo Horizonte: Instituto Casa da Educação Física/Unicamp/Fórum Pensamento Estratégico - PENSES, 2014a.

DIAS SOBRINHO, José. Universidade e novos modos de produção, circulação e aplicação do conhecimento. Avaliação: Revista da Avaliação da Educação Superior, v. 19, n. 3, Sorocaba, p. 643-62, nov. 2014b.

DIAS SOBRINHO, José. Educação superior, globalização e democratização: qual universidade? Revista Brasileira de Educação, n. 28, p. 164-73, p. 164-73, jan./abr. 2005.

FERNANDES, Florestan. Elementos da sociologia teórica. São Paulo: Editora Nacional/ Editora da USP, 1970.

FERREIRA, Nilda Teves. Cidadania: uma questão para a educação. Rio de Janeiro: Nova Fronteira, 1993.

FREIRE, Paulo. Educação e mudança. 21. ed. São Paulo: Paz e Terra, 1997.

GIDDENS, Anthony. Sociologia. 4. ed. Porto Alegre: Artmed, 2005.

GOERGEN, Pedro. Pós-modernidade, ética e educação. 2. ed. rev. Campinas, SP: Autores Associados, 2005.

GOERGEN, Pedro. Ensino Superior e formação: elementos de um olhar ampliado de avaliação. Avaliação: Revista de Avaliação da Educação Superior, Sorocaba, v. 6, n. 4, p. 63-76, 2001.

LAMARRA, Noberto Fernandes. Universidad, sociedad y conocimiento reflexiones para el debate. Avaliação: Revista de Avaliação da Educação Superior, Sorocaba, v. 19, n. 3, p. 663-88, nov. 2014. 
MARQUES, Waldemar. Brasil, terra de contrastes. Avaliação: Revista de Avaliação da Educação Superior, Sorocaba, v. 19, n. 3, p. 749-71, nov. 2014.

NAÇÕES UNIDAS BRASIL (ONU). Declaração Universal dos Direitos Humanos. Assembleia Geral das Nações Unidas em Paris, 10 dez. 1948. Disponível em: https://nacoesunidas. org/direitoshumanos/declaracao/. Acesso em: 21 abr. 2018.

PEREIRA, Caridade Maria dos Santos; PEDRO, Ana Paula. Escola, cidadania e formação de sujeitos éticos: os desafios da participação do aluno. Revista de Estudos UniversitáriosREU Sorocaba, v. 35, n. 2, p. 101-20, dez. 2009.

SACRISTÁN, José Gimeno. O currículo: uma reflexão sobre a prática. 3. ed. Porto Alegre: Artmed, 2000.

SANTOS, Fernando Ferreira dos. Princípios Constitucionais da dignidade da pessoa humana. São Paulo: Celso Bastos Editor/Instituto Brasileiro de Direito Constitucional, 1999.

SANTOS, Nair Iracema Silveira dos; LAZZAROTTO, Gislei Domingos Romanzini. Educação e cidadania: desafios para a universidade na construção de diálogos com as comunidades populares. Revista de Estudos Universitários-REU, Sorocaba, v. 33, n. 1, p. 77-88, jun. 2007.

TEIXEIRA, Anísio. Ensino Superior no Brasil: análise e interpretação de sua evolução até 1969. Rio de Janeiro: Editora da Fundação Getúlio Vargas, 1989.

\section{Sobre o autor:}

Pedro Laudinor Goergen: Pós-doutorado na Universidade de Bochum e no Instituto Max Planck da Alemanha. Doutorado em Filosofia - Ludwig Maximilians Universität München. Graduação em Filosofia pela Faculdade de Filosofia Ciências e Letras Nossa Senhora Imaculada Conceição. Professor titular da Universidade de Sorocaba (Uniso). E-mail: pedro.goergen@hotmail.com, Orcid: http://orcid.org/0000-0001-9539-9752

\section{Recebido em 30 de junho de 2019. \\ Aprovado em 1 de novembro de 2019}

